\title{
Integrated multi-omics data analysis identifying novel drug sensitivity-associated molecular targets of hepatocellular carcinoma cells
}

\author{
GOKHAN YILDIZ \\ Department of Medical Biology, Faculty of Medicine, Karadeniz Technical University, Trabzon 61080, Turkey
}

Received February 21, 2017; Accepted February 1, 2018

DOI: $10.3892 / \mathrm{ol} .2018 .8634$

\begin{abstract}
Hepatocellular carcinoma (HCC) is the most common type of liver cancer and the third-leading cause of malignancy-associated mortality worldwide. HCC cells are highly resistant to chemotherapeutic agents. Therefore, there are currently only two US Food and Drug Administration-approved drugs available for the treatment of HCC. The objective of the present study was to analyze the results of previously published high-throughput drug screening, and in vitro genomic and transcriptomic data from HCC cell lines, and to integrate the obtained results to define the underlying molecular mechanisms of drug sensitivity and resistance in HCC cells. The results of treatment with 225 different small molecules on 14 different HCC cell lines were retrieved from the Genomics of Drug Sensitivity in Cancer database and analyzed. Cluster analysis using the treatment results determined that $\mathrm{HCC}$ cell lines consist of two groups, according to their drug response profiles. Continued analyses of these two groups with Gene Set Enrichment Analysis method revealed 6 treatment-sensitive molecular targets (epidermal growth factor receptor, mechanistic target of rapamycin, deoxyribonucleic acid-dependent protein kinase, the Aurora kinases, Bruton's tyrosine kinase and phosphoinositide 3-kinase; all $\mathrm{P}<0.05$ ) and partially effective drugs. Genetic and genome-wide gene expression data analyses of the determined targets and their known biological partners revealed 2 somatically mutated and 13 differentially expressed genes, which differed between drug-resistant and drug-sensitive HCC cells. Integration of the obtained data into a short molecular pathway revealed a drug treatment-sensitive signaling axis in $\mathrm{HCC}$ cells. In conclusion, the results of the present study provide novel drug sensitivity-associated
\end{abstract}

Correspondence to: Dr Gokhan Yildiz, Department of Medical Biology, Faculty of Medicine, Karadeniz Technical University, 1 Farabi Street, Trabzon 61080, Turkey

E-mail: gokhanyildiz@ktu.edu.tr

Key words: liver cancer, drug target, drug sensitivity, bioinformatics analysis, targeted therapy molecular targets for the development of novel personalized and targeted molecular therapies against HCC.

\section{Introduction}

Hepatocellular carcinoma (HCC) is the most common type of liver cancer globally (1). It is also the sixth most frequently diagnosed type of neoplasm and the third most common cause of cancer associated-mortality globally (2). The late diagnosis of HCC at advanced stages of the disease $(3,4)$, the heterogeneous background of HCC cells (5) and high resistance of HCC cells to conventional chemotherapeutic agents $(3,6,7)$ are considered to be the primary reasons for the high mortality rates observed in patients with HCC.

At present, two drugs (sorafenib and regorafenib) are approved by the US Food and Drug Administration (FDA) for treatment of $\operatorname{HCC}(8,9)$. Sorafenib and regorafenib are multi-kinase targeting drugs, exhibiting only a moderate effect on HCC cells $(5,8)$. However, the initial approval of sorafenib by the FDA attracted attention to the development of novel targeted molecular therapies for the effective treatment of $\operatorname{HCC}(3,5,10)$. Thus far, the development of other systematic chemotherapeutic treatments for HCC has largely been unsuccessful $(11,12)$. The primary reason for this failure is a lack of comprehensive knowledge on the underlying molecular mechanisms responsible for drug sensitivity and the resistance of HCC cells to chemotherapeutic drugs. Thus, understanding of the underlying molecular mechanisms of the high resistance of advanced stage HCC cells, or the partial sensitivity of early-stage HCC cells to these drugs, requires resolution prior to development of successful novel chemotherapeutic treatments for HCC.

Previous developments in systematic high-throughput drug screening and genomic and transcriptomic profiling studies on cancer cell lines and patient tumor samples have provided a number of publicly available processed and unprocessed datasets, which are accessible through online databases (13-15). Analysis of these datasets may reveal previously unidentified effective small molecules and molecular targets, which may aid the development of novel strategies for cancer treatment. Integration of these separate datasets also enhances understanding of these pathways and mechanisms by revealing novel biological associations via systems biology approaches.

The purpose of the present study was to analyze publicly available drug screening results, genetic and gene expression 
datasets of in vitro $\mathrm{HCC}$ cell lines and to integrate the obtained data to define molecular players of drug sensitivity and resistance in HCC cells. Systematic drug treatment results, genomic alteration data and transcriptomic differences of 14 different HCC cell lines were analyzed, and the obtained results were integrated into a biological network. These analyses revealed that there were two sub-groups of HCC cells, which each responded differently to drug treatments. The results also provided more comprehensive data regarding drug sensitivity- and resistance-associated molecular targets in HCC cells, enabling the development of effective chemotherapeutic strategies.

\section{Materials and methods}

Cell lines and drug treatment results. The Z-score values of 225 different small molecule treatments on 14 HCC cell lines, 7 epithelial-like and 7 mesenchymal-like cell lines (Table I), were downloaded from Genomics of Drug Sensitivity in Cancer (GDSC) database (http://www.cancerrxgene.org/downloads; date of access, July 2016) (14). Each normalized Z-score value of a drug indicates the sensitivity (near to -2) or resistance (near to +2 ) of HCC cell lines to applied drug treatment.

Cluster analyses. The results of drug treatments were used during cluster analyses. Cluster analyses were performed using an unsupervised hierarchical average linkage clustering method with Cluster software (version 3.0) (16). Obtained results were visualized using Java Tree View software (version 1.1) (17).

Drug sets and Gene Set Enrichment Analysis (GSEA) experiments. Data used in the cluster analyses were re-processed for GSEA studies. Data from 18 small molecule treatments that were missing values for $\geq 25 \%$ of the samples ( 4 cell lines) were discarded to achieve true statistical results. The remaining 207 small molecule treatment datasets were utilized for GSEA studies. All small molecules used in the cluster analyses were grouped according to their known molecular targets to generate drug sets and run GSEA. A total of 33 drug sets, which include data concerning $\geq 3$ small molecules targeting the same biological molecule were generated and utilized during GSEA experiments (Table II). Drug treatment responses of Group A and Group B cells, which were divided by cluster analysis, were compared using generated drug sets and GSEA desktop software (version 2.2.3) with the Diff_of_Classes metric ranking method (18). P-values and false discovery rate (FDR) values for each drug set were generated using the GSEA software.

Determination of small molecule treatment sensitivity-associated somatic mutations. Lists of genes that are associated with the determined molecular targets [epidermal growth factor receptor (EGFR), mechanistic target of rapamycin (mTOR), DNA-dependent protein kinase (DNA-PK), aurora kinases (AURK), Bruton's tyrosine kinase (BTK) and phosphoinositide 3-kinase (PI3K); Table III] in different cellular pathways were downloaded from the Molecular Signatures Database (MSigDB; version 6.1; http://software.broadinstitute. org/gsea/msigdb; date of access, December 2017) (19). A total of 553 unique genes were determined. Somatic mutations
Table I. HCC cell lines analyzed in the present study.

\begin{tabular}{|c|c|c|c|}
\hline $\begin{array}{l}\text { Cell line } \\
\text { number }\end{array}$ & $\begin{array}{l}\text { Cell line } \\
\text { name }\end{array}$ & $\begin{array}{c}\text { HCC } \\
\text { sub-type }\end{array}$ & (Refs.) \\
\hline 1 & HEP3B & $\mathrm{E} / \mathrm{W}$ & $(72-74)$ \\
\hline 2 & HUH-7 & E/W & $(72-75)$ \\
\hline 3 & HUH-1 & $\mathrm{E} / \mathrm{W}$ & (75) \\
\hline 4 & HLE & $\mathrm{E} / \mathrm{U}$ & $(72,75,76)$ \\
\hline 5 & JHH-4 & $\mathrm{E} / \mathrm{W}$ & $(74,75)$ \\
\hline 6 & JHH-6 & $\mathrm{E} / \mathrm{W}$ & (75) \\
\hline 7 & JHH-7 & $\mathrm{E} / \mathrm{W}$ & (75) \\
\hline 8 & JHH-2 & $\mathrm{M} / \mathrm{P}$ & $(75)$ \\
\hline 9 & SNU-475 & $\mathrm{M} / \mathrm{P}$ & $(73,74)$ \\
\hline 10 & SNU-182 & $\mathrm{M} / \mathrm{P}$ & $(73,74)$ \\
\hline 11 & SNU-398 & $\mathrm{M} / \mathrm{P}$ & $(73,74)$ \\
\hline 12 & SNU-387 & $\mathrm{M} / \mathrm{P}$ & $(73,74)$ \\
\hline 13 & SNU-423 & $\mathrm{M} / \mathrm{P}$ & $(73,74)$ \\
\hline 14 & SNU-449 & $\mathrm{M} / \mathrm{P}$ & $(73,74)$ \\
\hline
\end{tabular}

High-throughput drug screening z-score results of 14 HCC cell lines were retrieved from GDSC database. Sub-types of the analyzed HCC cell lines are listed based on the literature, and the Japanese Collection of Research Bioresources Cell Bank and American Type Culture Collection databanks. E, epithelial-like; W, well differentiated; U, undifferentiated; M, mesenchymal-like; $\mathrm{P}$, poorly differentiated; HCC, hepatocellular carcinoma.

to these genes in $14 \mathrm{HCC}$ cell lines were screened using the Catalogue of Somatic Mutations in Cancer (COSMIC) database (versions 77 and 78; http://cancer.sanger.ac.uk/cosmic; date of access, September 2016) (15). Somatic mutation data for selected genes that were mutated exclusively in $>50 \%$ of a group are presented in Table IV.

Gene expression values of HCC cell lines. Whole transcriptome datasets from 14 HCC cell lines, which were generated by the Cancer Cell Line Encyclopedia (20) using Affymetrix Human Genome U133 Plus 2.0 gene chip arrays, were downloaded from Gene Expression Omnibus database (GSE36133 data series; https://www.ncbi.nlm.nih.gov/geo/query/acc. cgi?acc $=$ GSE36133) (13). Raw data were normalized using BRB Array Tools software (version 4.5.1) using a Robust Multi-Array Average quantile normalization method (21). Gene expression values of the aforementioned 553 genes, which were analyzed using the COSMIC database (15), were determined. Genes that exhibited $\geq 1.5$-fold and statistically significant $(\mathrm{P}<0.05)$ differential expression between Group A and Group B HCC cells were determined using the class comparison tool of the BRB Array Tools software, with default parameters (Table V).

Integrated pathway analysis. Pathway visualization analyses were performed using PathVisio Software (version 3.2.3) (22). Known molecular interactions of the differentially expressed and mutant genes were retrieved from Wikipathways (23), Consensus Path (24) and Kyoto Encyclopedia of genes and genomes databases (date of access, December 2016) (25); and integrated using PathVisio software. Visualization of the 
Table II. List of drug sets.

\begin{tabular}{|c|c|c|}
\hline Drug set name/molecular targets & Size & Small molecules of drug sets \\
\hline $\mathrm{PI} 3 \mathrm{~K}$ & 10 & $\begin{array}{l}\text { AS605240, AZD6482_1, AZD6482_2, BEZ235, CAL-101, } \\
\text { GDC0941, GSK2126458, PI-103, PIK-93, ZSTK474 }\end{array}$ \\
\hline HDAC & 9 & $\begin{array}{l}\text { AR-42, Belinostat, CAY10603, CUDC-101, JQ12, LAQ824, } \\
\text { Tubastatin_A, VNLG/124, Vorinostat }\end{array}$ \\
\hline EGFR & 7 & $\begin{array}{l}\text { Afatinib_1, Afatinib_2, Cetuximab, CUDC-101, EKB-569, } \\
\text { Gefitinib, OSI-930 }\end{array}$ \\
\hline KIT & 7 & $\begin{array}{l}\text { AMG-706, Axitinib, Masitinib, Midostaurin, OSI-930, Pazopanib, } \\
\text { XL-184 }\end{array}$ \\
\hline CDK9 & 6 & AT-7519, JNK-9L, KIN001-270, NG-25, THZ-2-49, TL-1-85 \\
\hline MEK1-2-5 & 6 & $\begin{array}{l}\text { BIX02189, PD-0325901, RDEA119_1, Selumetinib_1, } \\
\text { Selumetinib_2, Trametinib }\end{array}$ \\
\hline VEGFR & 6 & AMG-706, Axitinib, OSI-930, Pazopanib, Tivozanib, XL-184 \\
\hline JAK1-2-3 & 5 & CEP-701, KIN001-055, QL-X-138, Ruxolitinib, TG101348 \\
\hline PARP1-2 & 5 & AG-014699, Olaparib_1, Olaparib_2, Talazoparib, Veliparib \\
\hline PDGFR & 5 & AMG-706, Axitinib, MP470, OSI-930, Pazopanib \\
\hline AKT & 4 & AKT_inhibitor_VIII, GSK690693, KIN001-102, MK-2206 \\
\hline BRAF & 4 & Dabrafenib, PLX4720_1, PLX4720_2, SB590885 \\
\hline BRD2-3-4 & 4 & I-BET-762, JQ1_1, JQ1_2, PFI-1 \\
\hline CDK1-4-6-7-pan & 4 & PD-0332991, PHA-793887, RO-3306, THZ-2-102-1 \\
\hline FLT1-3-4 & 4 & AC220, CEP-701, WZ3105, XL-184 \\
\hline HSP70-90 & 4 & 17-AAG, AUY922, Elesclomol, SNX-2112 \\
\hline IGF1R & 4 & BMS-536924, BMS-754807, GSK1904529A, Lisitinib \\
\hline IKK & 4 & BMS345541, BX-795, KIN001-260, TPCA-1 \\
\hline Microtubules & 4 & Docetaxel, Epothilone_B, Vinblastine, Vinorelbine \\
\hline ALK & 3 & CH5424802, SB505124, SB52334 \\
\hline AURK & 3 & BX-795, Genentech_Cpd_10, GSK1070916 \\
\hline BCL2-XL-W & 3 & Navitoclax, Obatoclax_Mesylate, TW-37 \\
\hline BTK & 3 & LFM-A13, QL-X-138, QL-XII-47 \\
\hline DNA-PK & 3 & NU-7441, PI-103, QL-X-138 \\
\hline ERBB2 & 3 & Afatinib_1,Afatinib_2, CP724714 \\
\hline JNK & 3 & AS601245, JNK-9L, JNK_Inhibitor_VIII \\
\hline MDM2 & 3 & JNJ-26854165, NSC-207895, Nutlin-3a (-) \\
\hline mTOR & 3 & GSK2126458, QL-X-138, Temsirolimus \\
\hline mTORC1-2 & 3 & AZD8055, BEZ235, OSI-027 \\
\hline PDK1 & 3 & BX-912, KIN001-244, OSU-03012 \\
\hline RET & 3 & AMG-706, CEP-701, XL-184 \\
\hline ROCK1-2 & 3 & GSK269962A, GSK429286A, Y-39983 \\
\hline TOP1-2 & 3 & Camptothecin, Etoposide, SN-38 \\
\hline
\end{tabular}

A total of 33 drug sets, which include $\geq 3$ different small molecule treatments that have the same biological target. Size refers to the total number of small molecule treatment results in the drug set.

differentially expressed genes was performed based on the microarray gene expression results.

\section{Results}

HCC cell lines consist of two groups according to their drug response profiles. To identify drug treatment response characteristics of HCC cell lines and determine effective drugs and molecular targets for the treatment of HCC, small molecule treatment Z-score values of $14 \mathrm{HCC}$ cell lines were downloaded from the GDSC database (14). Results of 225 treatments on 14 HCC cell lines were analyzed using the aforementioned clustering method to determine the global treatment response profiles of HCC cells. Unsupervised hierarchical clustering analysis revealed two main groups of HCC cell lines according to their sensitivity to drug treatments (Fig. 1). The first group of HCC cells, Group A cells, was comprised of 7 epithelial-like HCC cell lines; whereas the second group, Group B cells, was comprised of 7 mesenchymal-like HCC cells (Table I). This result indicates that although all cells analyzed were 
Table III. List of significantly enriched drug sets.

\begin{tabular}{llcccc}
\hline Rank & Name & Size & ES & $\begin{array}{c}\text { NOM } \\
\text { P-value }\end{array}$ & $\begin{array}{c}\text { FDR } \\
\text { q-value }\end{array}$ \\
\hline 1 & EGFR & 7 & 0.869 & 0.007 & 0.151 \\
2 & mTOR & 3 & 0.957 & 0.013 & 0.118 \\
3 & DNA-PK & 3 & 0.957 & 0.016 & 0.136 \\
4 & AURK & 3 & 0.952 & 0.016 & 0.164 \\
5 & BTK & 3 & 0.902 & 0.039 & 0.173 \\
6 & PI3K & 10 & 0.829 & 0.046 & 0.218 \\
\hline
\end{tabular}

Among all 33 drug sets, 6 (18\%) were statistically significantly $(\mathrm{P}<0.05$ and $\mathrm{FDR}<0.25)$ enriched in Group A HCC cells. Drug sets were ranked according to their P-value scores. ES, enrichment score; NOM, nominal; FDR, false discovery rate; EGFR, epidermal growth factor receptor; mTOR, mechanistic target of rapamycin; DNA-PK, deoxyribonucleic acid-dependent protein kinase; AURK, aurora kinases; BTK, bruton tyrosine kinase; PI3K, phosphoinositide 3-kinase; HCC, hepatocellular carcinoma.

HCC cells, epithelial-like and mesenchymal-like HCC cells responded differently to the same drug treatments.

Effective molecular targets of drug-sensitive Group A epithelial-like HCC cells were identified. To determine the list of molecular targets, which are associated with the treatment response characteristics of Group A and Group B cells, GSEA studies were performed. Since GSEA compares two sample groups and determines statistically significantly enriched sets in each group, 33 drug sets that included $\geq 3$ different small molecules with the same biological target were generated using the data downloaded from GDSC (Table II). GSEA results revealed that $28 / 33$ drug sets $(85 \%)$ were enriched (effective) on Group A cells, and that 6 of them (18\%) were significantly enriched $(\mathrm{P}<0.05$; Table III); whereas the remaining 5 drug sets (15\%) were enriched in Group B cells; however, none of them were statistically significant. The significantly drug-sensitive molecular targets in Group A HCC cells were; EGFR, mTOR, DNA-PK, AURK, BTK and PI3K (Table III). Therefore, GSEA results identified molecular targets and drugs associated with drug sensitivity in epithelial-like Group A HCC cells.

Somatic mutations associated with treatment response profiles of Group A and Group B HCC cells were determined. To identify genetic factors that were possibly associated with drug sensitivity in Group A cells and drug resistance of Group B cells, genetic variation data (somatic mutations, fusions, breakpoints) of all genes biologically function with the determined 6 molecular targets were analyzed. First, a list of all biologically functioning genes with 6 determined molecular targets was retrieved from MSigDB. A total of 553 unique genes, which directly or indirectly interact with the determined molecular target in at least one signaling pathway, were identified. Genetic variation data of all 553 genes in $14 \mathrm{HCC}$ cell lines were assessed using the COSMIC database. The two genes that were exclusively mutated in $>50 \%$ of a group were considered to be potentially associated with the drug response profile of HCC cell lines and groups (Table IV). The inositol 1,4,5-trisphosphate receptor type 2 (ITPR2) gene exhibited 5 distinct mutations in 4 Group A HCC cell lines (HUH-7, JHH-6, JHH-7 and HEP3B); whereas phosphoinositide-3-kinase regulatory subunit 4 (PIK3R4) gene exhibited 4 distinct mutations in 4 Group B HCC cell lines (JHH-2, SNU-182, SNU-387, SNU-423; Table IV). As a result, 553 genes that function with the 6 determined molecular targets were identified; and 2 genes with somatic mutations possibly associated with small molecule treatment responses of Group A and Group B HCC cells were identified.

Molecular targets and highly differentially expressed genes were determined. To identify differentially expressed genes that had potential functions in sensitivity and resistance responses of Group A and Group B HCC cells, respectively, when the determined 6 molecules were targeted, whole genome transcriptomics data of the same 14 HCC cell lines were downloaded and analyzed. Gene expression profiles of the aforementioned 553 genes were determined for Group A and Group B HCC cells, and 13 genes that exhibited $\geq 1.5$-fold and statistically significant $(\mathrm{P}<0.05)$ differential expression between the two groups were selected (Table V). Among the 13 selected genes, 6 genes were upregulated in Group A HCC cells, and 7 genes were upregulated in Group B HCC cells (Table V). In conclusion, gene expression profiles of untreated Group A and Group B HCC cells were determined and 13 differentially expressed genes associated with previously defined molecular targets were identified.

Integrated multi-omics results of Group A HCC cells revealed a drug-sensitive molecular network of HCC. To identify a simple molecular interaction network of drug-sensitive molecular targets for Group A HCC cells, the determined pharmacogenomics and transcriptomic results were integrated into one molecular pathway. Enriched drug targets and drugs (Table III), mutant genes (Table IV) and differentially expressed genes (Table V) results for drug-sensitive Group A HCC cell lines were integrated into one pathway and visualized based on their known interactions in pathway databases (23-25) (Fig. 2). The integration of multi-omics data of Group A HCC cells revealed the molecular network of drug-sensitive HCC cells (Fig. 2).

\section{Discussion}

The FDA approval of the multi-kinase inhibitor sorafenib for the treatment of HCC led to an acceleration in the search for effective molecular targets and molecularly targeted chemotherapeutic drugs against HCC. Thus far, only one additional drug, regorafenib, has been approved for HCC treatment by the FDA. The complex and heterogeneous characteristics of HCC cells are considered to be among the main obstacles to identification of effective drugs for use against HCC (26). The present study determined that there were two main subgroups of HCC cells in terms of drug treatment response profiles (Fig. 1). The first group (Group A) consisted of epithelial-like HCC cells, and the second group (Group B) consisted of mesenchymal-like HCC cells (Fig. 1; Table I). Mesenchymal-like HCC cells emerge following epithelial-to-mesenchymal transition, and their presence corresponds to an advanced stage of HCC (27). 
Table IV. Somatic mutations, possibly associated with drug response profiles of hepatocellular carcinoma cell lines and Groups.

\begin{tabular}{|c|c|c|c|c|c|c|c|c|c|}
\hline Gene & $\begin{array}{c}\text { Mutant cell } \\
\text { lines, } \mathrm{n}\end{array}$ & $\begin{array}{l}\text { Cell } \\
\text { line }\end{array}$ & Group & AA mutation & Transcript ID & $\begin{array}{c}\text { CDS } \\
\text { mutation }\end{array}$ & Zygosity & Val. & $\begin{array}{l}\text { Mut. } \\
\text { type }\end{array}$ \\
\hline \multirow[t]{5}{*}{ ITPR2 } & \multirow[t]{5}{*}{4} & HUH-7 & $\mathrm{A}$ & p.L1859L & ENST00000381340 & c. $5577 \mathrm{~A}>\mathrm{G}$ & Het. & $\mathrm{U}$. & S.-C. \\
\hline & & JHH-6 & A & p.T969I & ENST00000381340 & c. $2906 \mathrm{C}>\mathrm{T}$ & Het. & V. & S.-M. \\
\hline & & JHH-7 & A & p.E1614_M1621>V & ENST00000381340 & c.4841_4861del21 & Het. & V. & Comp. \\
\hline & & HEP3B & A & p.T728N & ENST00000381340 & c. $2183 \mathrm{C}>\mathrm{A}$ & Het. & U. & S.-M. \\
\hline & & HEP3B & A & p.V1508I & ENST00000381340 & c. $4522 \mathrm{G}>\mathrm{A}$ & Het. & U. & S.-M. \\
\hline \multirow[t]{4}{*}{ PIK3R4 } & \multirow[t]{4}{*}{4} & JHH-2 & B & p.D473V & ENST00000356763 & c. $1418 \mathrm{~A}>\mathrm{T}$ & Het. & V. & S.-M. \\
\hline & & SNU-182 & B & p.R1033S & ENST00000356763 & c. $3099 \mathrm{~A}>\mathrm{T}$ & Het. & V. & S.-M. \\
\hline & & SNU-387 & $\mathrm{B}$ & p.R495R & ENST00000356763 & c. $1483 \mathrm{~A}>\mathrm{C}$ & Het. & $\mathrm{U}$. & S.-C. \\
\hline & & SNU-423 & B & p.V345F & ENST00000356763 & c. $1033 \mathrm{G}>\mathrm{T}$ & Het. & V. & S.-M. \\
\hline
\end{tabular}

AA, amino acid; CDS, coding sequence; Val., validation status; Mut, mutation; Het, heterozygous; U, unvalidated; V, validated; S.- M, substitution-missense; S.- C, substitution-coding silent; Comp, complex-deletion inframe; ITPR2, inositol 1,4,5-trisphosphate receptor type 2; PIK3R4, phosphoinositide-3-kinase regulatory subunit 4.

Table V. List of 13 differentially expressed genes between Group A and Group B HCC cells.

\begin{tabular}{|c|c|c|c|c|c|c|c|}
\hline Rank & ProbeSet & Gene symbol & Group A & Group B & Fold change & P-value & FDR \\
\hline 1 & 226213_at & ERBB3 & 9.39 & 5.54 & 3.85 & 0.002 & 0.12 \\
\hline 2 & 228912_at & VIL1 & 7.33 & 4.15 & 3.19 & 0.015 & 0.22 \\
\hline 3 & 228716_at & THRB & 8.79 & 6.77 & 2.03 & 0.001 & 0.07 \\
\hline 4 & 232530_at & PLD1 & 7.90 & 6.07 & 1.83 & 0.001 & 0.11 \\
\hline 5 & 238441_at & PRKAA2 & 7.84 & 6.13 & 1.72 & 0.001 & 0.07 \\
\hline 6 & 202609_at & EPS8 & 11.37 & 9.83 & 1.54 & 0.014 & 0.22 \\
\hline 7 & 38037_at & HBEGF & 6.00 & 7.60 & -1.61 & 0.005 & 0.14 \\
\hline 8 & 219383_at & PRR5L & 5.04 & 6.69 & -1.65 & 0.009 & 0.18 \\
\hline 9 & 202742_s_at & PRKACB & 7.67 & 9.38 & -1.71 & 0.001 & 0.10 \\
\hline 10 & 203085_s_at & TGFB1 & 7.97 & 9.75 & -1.78 & 0.014 & 0.22 \\
\hline 11 & 212912_at & RPS6KA2 & 3.68 & 6.08 & -2.40 & 0.006 & 0.14 \\
\hline 12 & 1556499_s_at & COL1A1 & 7.10 & 11.85 & -4.76 & 0.006 & 0.14 \\
\hline 13 & 201842_s_at & EFEMP1 & 6.14 & 10.94 & -4.81 & 0.005 & 0.14 \\
\hline
\end{tabular}

A total of 13/553 genes were $\geq 1.5$-fold differentially expressed between two groups. Among 13 significantly $(\mathrm{P}<0.05$ and FDR $<0.25)$ differentially expressed genes, six of them were upregulated in Group A cells, while seven genes were upregulated in Group B cells. Genes were ranked according to their fold-change values. FDR, false discovery rate; HCC, hepatocellular carcinoma.

In contrast, the epithelial-like HCC cells retain the original hepatocyte epithelial morphology. These two groups of HCC cells exhibited distinct sensitivities to identical drug treatments. There was no drug that was effective on all HCC cell types among the 225 small molecules analyzed.

A comparison of drug treatment responses of the two groups via GSEA revealed the molecular targets sensitive to drug treatment in the two groups of HCC cells (Table III). GSEA results demonstrated that Group A cells, which are comprised of early-stage HCC cells, are more sensitive than Group B cells, which are comprised of advanced-stage HCC cells, to small molecule treatments that target six molecules (Table III). Thus, targeting these molecules with the analyzed drugs cannot yield successful results in advanced-stage
HCC cells, but it may be a useful strategy for the treatment of early-stage HCC cells. Since the majority of the identified treatment-sensitive molecular targets in the present study have been studied previously as potential treatment targets for HCC and other types of cancer $(10,11,28)$, it is known that they are ineffective targets in HCC cells, although drugs targeting these molecules are effective in other types of cancer, $(5,26)$. In addition, the results of the present study indicated that early-stage HCC cells are more sensitive to drug treatments that advanced-stage HCC cells. Thus, the identification of altered molecular mechanisms and novel molecules responsible for the observed differences between the two groups of HCC cells is required to improve treatment outcomes. The results of GSEA in the present study provide valuable information to further 


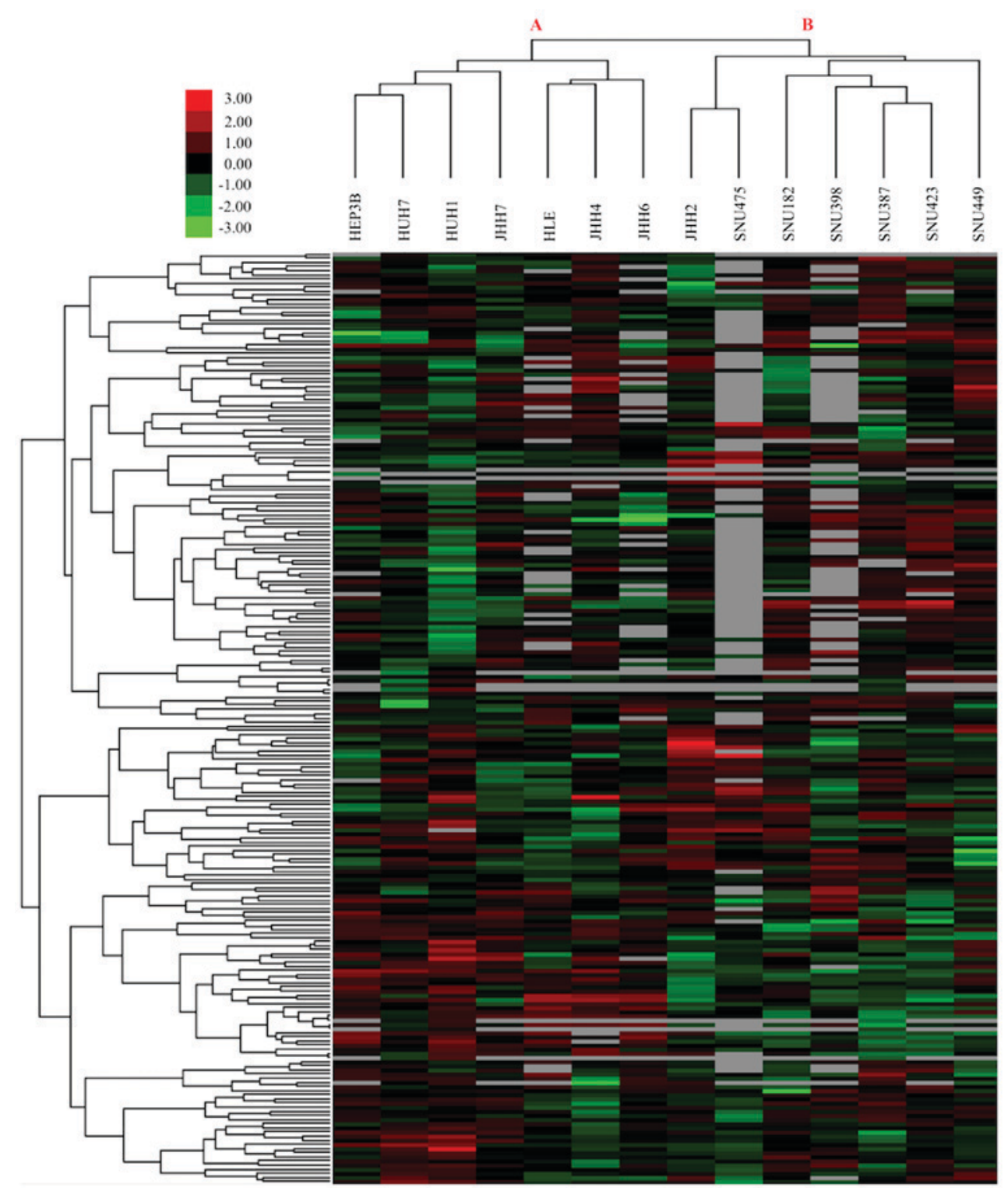

Figure 1. Results of cluster analysis for 225 drug treatments in 14 HCC cell lines. A heatmap was generated using drug treatment Z-score values of HCC cell lines. Unsupervised clustering of small molecules and samples resulted in two main sample clusters, Group A and Group B. Each group comprises 7 cell lines. Red, resistant; green, sensitive; grey, missing value; HCC, hepatocellular carcinoma.

analyze and understand the underlying molecular mechanisms of drug sensitivity and resistance in HCC cells. Therefore, molecules that cooperate with the defined molecular targets and genes that are somatically mutated (Table IV) and differentially expressed were determined (Table V).

The PI3K/RAC serine/threonine-protein kinase $(\mathrm{AKT}) / \mathrm{mTOR}$ signaling pathway serves a function in cell growth, proliferation, angiogenesis, metabolism and mechanisms of anti-apoptosis in hepatocytes (29-31). The data in the present study revealed that mTOR and PI3K are effective molecular targets for the treatment of epithelial-like (early) HCC cells, but not for mesenchymal-like (advanced) HCC cells. PI3K may be activated following the activation of certain receptors, including the insulin receptor and EGFR, which is another target molecule identified in the present study $(32,33)$. Active PI3K catalyzes the generation of phosphatidylinositol $(3,4,5)$-trisphosphate (PIP3) from phosphatidylinositol (4,5)-bisphosphate (PIP2) and causes the activation of AKT (34-36). Activated AKT phosphorylates and activates several molecules, including mTOR $(29,35)$. Active mTOR increases cell proliferation, survival and angiogenesis as a component of mTOR complex 1 (mTORC1) and mTORC2 $(36,37)$. This signaling pathway is negatively regulated by phosphatase and tensin homolog $(35,38)$. The PI3K/AKT/mTOR pathway is activated in $15-41 \%$ of HCCs, and inhibitors of this signaling pathway exhibited anti-neoplastic activities in experimental HCC models (11). The results of the present study identified that the EGFR/PI3K/AKT/mTOR signaling pathway serves a central function in the regulation of drug sensitivity and resistance in HCC cells (Fig. 2; Table III).

BTK is a non-receptor intracellular kinase that is mainly expressed in B-lymphocytes. BTK functions via B-cell receptor (BCR) signaling and the PI3K/AKT pathway. Antigen-bound BCRs bind to Lck/Yes novel kinase and spleen tyrosine kinase, and phosphorylate and activate PI3K, which converts PIP2 to 


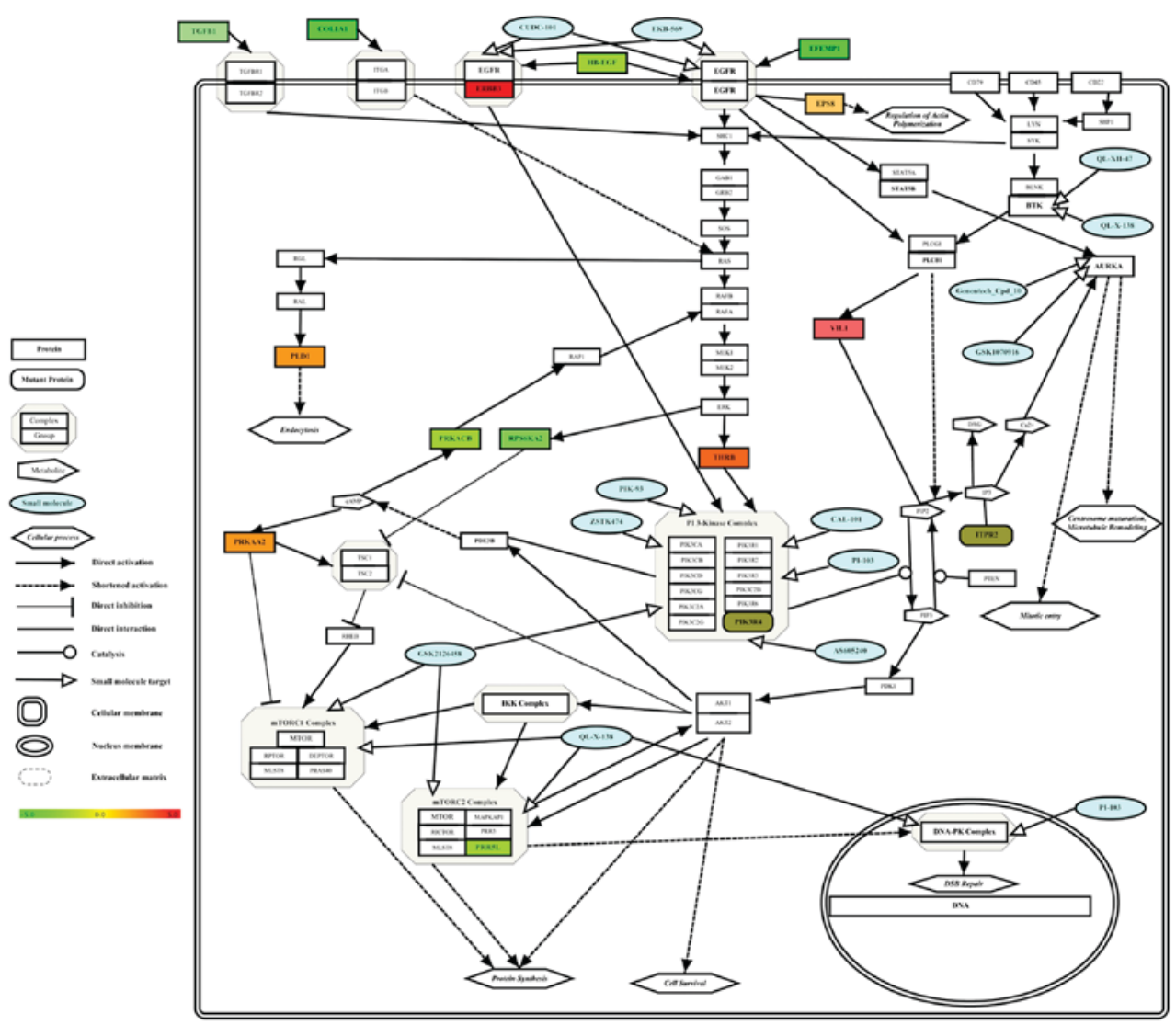

Figure 2. Integrated molecular pathway of small molecule sensitivity in Group A HCC cell lines. Effective drugs (in blue color), enriched drug targets (Table III), target-associated somatically mutant genes (Table IV) and differentially expressed genes (Table V) in HCC cell lines were integrated into one pathway and visualized. Gene expression levels are depicted in a color gradient between -5 (downregulated, color) and +5 (upregulated, red) by the software, as indicated by the color bar. Gene Symbols were retrieved from Human Genome Organisation Gene Nomenclature Committee (71) using the software. PIP3, phosphatidylinositol (3,4,5)-trisphosphate; PIP2, phosphatidylinositol (4,5)-bisphosphate; IP3, inositol trisphosphate; DAG, diacylglycerol; cAMP, cyclic adenosine monophosphate; ER, endoplasmic reticulum; HCC, hepatocellular carcinoma.

PIP3, to which BTK and AKT proteins bind. Numerous BTK inhibitors have exhibited promising therapeutic activities in hematological malignancies; however, further studies are required to identify the roles of BTK in HCC (39).

Aurora kinases (AURKA, AURKB and AURKC) are serine/threonine kinases that control cell division. These kinases serve a pivotal function during the mitotic phase of the cell cycle and are targeted by small molecule inhibitors. AURKC is expressed in the testes, whereas AURKA and AURKB may serve functions in different sub-cellular compartments. However, all three Aurora proteins perform crucial functions during chromosomal arrangement and the control processes of mitotic spindle apparatus formation (40). In addition, all three proteins are overexpressed in numerous types of cancer (41). In cancer cells, including HCC, Aurora kinases inhibit apoptosis and promote cellular proliferation and metastasis (42). AURKA is directly associated with the EGFR/PI3K/Akt/mTOR pathway, since active EGFR signaling is able to upregulate expression of AURKA through the FR/PI3K/Akt/mTOR signaling axis (43).

DNA-PK is a multi-protein complex that is primarily comprised of Ku70 [encoded by X-ray repair cross complementing 6 (XRCC6)], Ku80 (encoded by XRCC5) and the catalytic subunit DNA-PK catalytic subunit (DNA-PKcs), which is encoded by protein kinase DNA-activated catalytic polypeptide (44). DNA-PKcs may be activated following DNA damage (44-46); it serves a pivotal function in the non-homologous end-joining mechanism of DNA double-strand break repair $(47,48)$. It has been identified that DNA-PK serves a function in the initiation and progression of cancer, and the therapeutic resistance of multiple types of cancer, including HCC (49-52). DNA-PK directly interacts with AKT and increases its activity $(53,54)$. Therefore, DNA-PK may function independently as a member of the PI3K-AKT-mTOR axis. In conclusion, all 6 drug sensitivity-associated targets identified via GSEA study are biologically functional together in the EGFR-PI3K-mTOR-DNAPK signaling axis, and targeting this axis renders early-stage Group A HCC cells sensitive to drug treatments, but not advanced-stage Group B HCC cells.

Following identification of the central signaling axis, known genomic variants of the same $14 \mathrm{HCC}$ cells associated with the drug response profiles of Group A and Group B cells were analyzed. Following analysis of genomic variation using the COSMIC database, somatic mutations to 2 genes were determined as possibly biologically associated, since ITPR2 and PIK3R4 genes are exclusively mutated in Group A and Group B cells, respectively (Table IV).

The ITPR2 gene, which encodes a receptor of IP3, is mutated in 4 Group A cell lines (HUH-7, JHH-6, JHH-7 and HEP3B; $\mathrm{P}=0.039$; Table IV). Upregulated ITPR2 
expression is a biomarker of poor prognosis in patients with acute myeloid leukemia (55). ITPR2 was also identified as a susceptibility gene for Kashin-Beck disease (56). ITPR 2 may cause an increase of cytoplasmic calcium following binding to IP3 (57); it also serves functions in oncogene-induced senescence and replicative senescence by regulating calcium levels, and the loss of ITPR2 causes escape from cellular senescence (57). Since cellular senescence is a mechanism of hepatocellular carcinogenesis (58), the effect of the identified ITPR 2 mutation on HCC cells should be further investigated.

PIK3R4, which encodes the serine/threonine-protein kinase VPS15, exhibited 4 distinct mutations in 4 Group B HCC cell lines (JHH-2, SNU-182, SNU-387, SNU-423; $\mathrm{P}=0.039$; Table IV). PIK3R4 functions with protein kinase AMP-activated catalytic subunit $\alpha 2$ (PRKAA2; one of the genes upregulated in Group A HCC cells) in the autophagy pathway (25), indicating that it may serve a role in the drug sensitivity of Group A HCC cells. PIK3R4 is also a member of the PI $3 \mathrm{~K}$ complex, and serves a function in autophagy as a member of the class III PI3K complex (59). The over-expression of the PIK3R4 gene in patients with chronic lymphocytic leukemia (CML) has been associated with the prognosis of CML (60). This gene has also been identified to be mutated in certain thymic epithelial tumors and metastatic melanoma samples $(61,62)$. Copy number aberrations of PIK3R4 have been associated with decreased survival rates of patients with ovarian cancer (63). The statistically significant presence of mutated PIK3R4 in the treatment-resistant Group B cells indicates the possible function served by PIK3R4 mutations in the drug response profiles of HCC cells.

Transcriptomics analyses on HCC cells revealed that six genes are significantly upregulated and seven genes are downregulated in Group A cells (Table V). Roles of the transcriptionally deregulated genes in drug sensitivity of Group A cells require further study. Supporting this hypothesis, the activation of PRKAA2 protein sensitizes HCC cells to a number of drug treatments (64-67). Thus, the upregulation of PRKAA2 in drug-sensitive HCC cells may serve a central function in the observed response to treatment. For the other genes differentially upregulated in Group A HCC cells, there is a limited amount of available data concerning the effects of their transcriptional upregulation in HCC. Upregulated expression of villin 1 was identified as a predictive factor for the recurrence of high serum $\alpha$-fetoprotein-associated HCC following hepatectomy (68). Erb-B2 receptor tyrosine kinase 3 (ERBB3) mRNA was upregulated in 52\% of HCC tumors (69), and secreted ERBB3 isoforms were identified as serum markers for early hepatoma in patients with chronic hepatitis and cirrhosis (70). Therefore, the roles of these genes in drug sensitivity and resistance mechanisms of HCC cells should be studied further.

Since all the treatment-sensitive molecular targets identified possess biological functions, and the mutated and differentially expressed genes are also associated with these molecules, the results of multi-omics data analysis were integrated into a simple molecular interaction network to analyze the treatment sensitivity-associated molecular mechanisms of HCC cells better (Fig. 2). This shortened, drug treatment sensitivity-associated molecular network of HCC cells can be used to generate novel hypotheses for further experimentation to reveal the underlying molecular mechanisms of drug sensitivity and resistance in HCC cells. For example, since the integrated molecular network identifies the molecular pathway of Group A HCC cells (Fig. 2), which are sensitive to treatments with drugs depicted in green, it may be of interest to examine whether activation of the EGFR-PI3K-mTOR-DNAPK axis via external or constitutively active internal signals in Group B HCC cells renders them sensitive to the same drugs. This approach may provide valuable information, enabling the development of novel combined drug treatment approaches against advanced-stage $\mathrm{HCC}$ cells.

In conclusion, the results of high-throughput drug treatment experiments on HCC cells analyzed in the present study indicate that molecular targeted, personalized chemotherapeutic approaches should be developed for the treatment of HCC, since distinct HCC cell types respond differently to the same drug treatments. Novel molecular targets and their biological associations identified in the present study should be further investigated to develop targeted molecular drug therapies against HCC.

\section{Acknowledgements}

Not applicable.

\section{Funding}

No funding was received.

\section{Availability of data and materials}

All datasets analyzed during the present study are available in cited public databases. All data analyzed during the present study are included in the published article.

\section{Authors' contributions}

GY analyzed the data and wrote the manuscript.

\section{Ethics approval and consent to participate}

Not applicable.

\section{Consent for publication}

Not applicable.

\section{Conflict of interest}

The author declares that there are no competing interests.

\section{References}

1. McGlynn KA, Petrick JL and London WT: Global epidemiology of hepatocellular carcinoma: An emphasis on demographic and regional variability. Clin Liver Dis 19: 223-238, 2015.

2. Torre LA, Bray F, Siegel RL, Ferlay J, Lortet-Tieulent J and Jemal A: Global cancer statistics, 2012. CA Cancer J Clin 65: 87-108, 2015.

3. Shin JW and Chung YH: Molecular targeted therapy for hepatocellular carcinoma: Current and future. World J Gastroenterol 19: 6144-6155, 2013. 
4. Balogh J, Victor D III, Asham EH, Burroughs SG, Boktour M, Saharia A, Li X, Ghobrial RM and Monsour HP Jr: Hepatocellular carcinoma: A review. J Hepatocell Carcinoma 3: 41-53, 2016.

5. Colagrande S, Inghilesi AL, Aburas S, Taliani GG, Nardi C and Marra F: Challenges of advanced hepatocellular carcinoma. World J Gastroenterol 22: 7645-7659, 2016.

6. Barranco SC, Haenelt BR and Gee EL: Differential sensitivities of five rat hepatoma cell lines to anticancer drugs. Cancer Res 38: 656-660, 1978

7. Ferroudj S, Yildiz G, Bouras M, Iscan E, Ekin U and Ozturk M: Role of fanconi anemia/BRCA pathway genes in hepatocellular carcinoma chemoresistance. Hepatol Res 46: 1264-1274, 2016.

8. Llovet JM, Ricci S, Mazzaferro V, Hilgard P, Gane E, Blanc JF, de Oliveira AC, Santoro A, Raoul JL, Forner A, et al: Sorafenib in advanced hepatocellular carcinoma. N Engl J Med 359: 378-390, 2008

9. Bruix J, Qin S, Merle P, Granito A, Huang YH, Bodoky G, Pracht M, Yokosuka O, Rosmorduc O, Breder V, et al: Regorafenib for patients with hepatocellular carcinoma who progressed on sorafenib treatment (RESORCE): A randomised, double-blind, placebo-controlled, phase 3 trial. Lancet 389: 56-66, 2017.

10. Chacko S and Samanta S: Hepatocellular carcinoma: A life-threatening disease. Biomed Pharmacother 84: 1679-1688, 2016.

11. Montella L, Palmieri G, Addeo R and Del Prete S: Hepatocellular carcinoma: Will novel targeted drugs really impact the next future? World J Gastroenterol 22: 6114-6126, 2016.

12. Villanueva A, Hernandez-Gea V and Llovet JM: Medical therapies for hepatocellular carcinoma: A critical view of the evidence. Nat Rev Gastroenterol Hepatol 10: 34-42, 2013

13. Barrett T, Wilhite SE, Ledoux P, Evangelista C, Kim IF, Tomashevsky M, Marshall KA, Phillippy KH, Sherman PM, Holko M, et al: NCBI GEO: Archive for functional genomics data sets-update. Nucleic Acids Res 41 (Database Issue): D991-D995, 2013.

14. Yang W, Soares J, Greninger P, Edelman EJ, Lightfoot H, Forbes S, Bindal N, Beare D, Smith JA, Thompson IR, et al: Genomics of Drug sensitivity in cancer (GDSC): A resource for therapeutic biomarker discovery in cancer cells. Nucleic Acids Res 41 (Database Issue): D955-D961, 2013.

15. Forbes SA, Beare D, Gunasekaran P, Leung K, Bindal N, Boutselakis H, Ding M, Bamford S, Cole C, Ward S, et al: COSMIC: Exploring the world's knowledge of somatic mutations in human cancer. Nucleic Acids Res 43 (Database Issue): D805-D811,2015

16. de Hoo MJ, Imoto S, Nolan J and Miyano S: Open source clustering software. Bioinformatics 20: 1453-1454, 2004.

17. Saldanha AJ: Java Treeview-extensible visualization of microarray data. Bioinformatics 20: 3246-3248, 2004.

18. Subramanian A, Tamayo P, Mootha VK, Mukherjee S, Ebert BL, Gillette MA, Paulovich A, Pomeroy SL, Golub TR, Lander ES and Mesirov JP: Gene set enrichment analysis: A knowledge-based approach for interpreting genome-wide expression profiles. Proc Natl Acad Sci USA 102: 15545-15550, 2005.

19. Liberzon A, Subramanian A, Pinchback R, Thorvaldsdóttir $H$, Tamayo P and Mesirov JP: Molecular signatures database (MSigDB) 3.0. Bioinformatics 27: 1739-6140, 2011.

20. Barretina J, Caponigro G, Stransky N, Venkatesan K, Margolin AA, Kim S, Wilson CJ, Lehár J, Kryukov GV, Sonkin D, et al: The cancer cell line encyclopedia enables predictive modelling of anticancer drug sensitivity. Nature 483: 603-607, 2012

21. Simon R, Lam A, Li MC, Ngan M, Menenzes S and Zhao Y: Analysis of gene expression data using BRB-ArrayTools. Cancer Inform 3: 11-17, 2007

22. Kutmon M, van Iersel MP, Bohler A, Kelder T, Nunes N, Pico AR and Evelo CT: PathVisio 3: An extendable pathway analysis toolbox. PLoS Comput Biol 11: e1004085, 2015.

23. Kutmon M, Riutta A, Nunes N, Hanspers K, Willighagen EL, Bohler A, Mélius J, Waagmeester A, Sinha SR, Miller R, et al: WikiPathways: Capturing the full diversity of pathway knowledge. Nucleic Acids Res 44: D488-D494, 2016.

24. Kamburov A, Stelzl U, Lehrach $\mathrm{H}$ and Herwig R: The ConsensusPathDB interaction database: 2013 update. Nucleic Acids Res 41 (Database Issue): D793-D800, 2013.

25. Kanehisa M and Goto S: KEGG: Kyoto encyclopedia of genes and genomes. Nucleic Acids Res 28: 27-30, 2000.

26. Chen C and Wang G: Mechanisms of hepatocellular carcinoma and challenges and opportunities for molecular targeted therapy. World J Hepatol 7: 1964-1970, 2015.
27. Kojiro M: Histopathology of liver cancers. Best Pract Res Clin Gastroenterol 19: 39-62, 2005.

28. Lachenmayer A, Alsinet C, Chang CY and Llovet JM: Molecular approaches to treatment of hepatocellular carcinoma. Dig Liver Dis 42 (Suppl 3): S264-S272, 2010.

29. Zhou Q, Lui VW and Yeo W: Targeting the PI3K/Akt/mTOR pathway in hepatocellular carcinoma. Future Oncol 7: 1149-1167, 2011.

30. Sieghart W, Fuereder T, Schmid K, Cejka D, Werzowa J, Wrba F, Wang X, Gruber D, Rasoul-Rockenschaub S, Peck-Radosavljevic $\mathrm{M}$ and Wacheck V: Mammalian target of rapamycin pathway activity in hepatocellular carcinomas of patients undergoing liver transplantation. Transplantation 83: 425-432, 2007.

31. Villanueva A, Chiang DY, Newell P, Peix J, Thung S, Alsinet C, Tovar V, Roayaie S, Minguez B, Sole M, et al: Pivotal role of mTOR signaling in hepatocellular carcinoma. Gastroenterology 135: 1972-1983, 2008.

32. Huynh H: Molecularly targeted therapy in hepatocellular carcinoma. Biochem Pharmacol 80: 550-560, 2010.

33. Wysocki PJ: Targeted therapy of hepatocellular cancer. Expert Opin Investig Drugs 19: 265-274, 2010.

34. Thorpe LM, Yuzugullu H and Zhao JJ: PI3K in cancer: Divergent roles of isoforms, modes of activation and therapeutic targeting. Nat Rev Cancer 15: 7-24, 2015.

35. Dibble CC and Cantley LC: Regulation of mTORC1 by PI3K signaling. Trends Cell Biol 25: 545-55, 2015.

36. Zoncu R, Efeyan A and Sabatini DM: mTOR: From growth signal integration to cancer, diabetes and ageing. Nat Rev Mol Cell Biol 12: 21-35, 2011

37. Laplante M and Sabatini DM: mTOR signaling in growth control and disease. Cell 149: 274-293, 2012.

38. Vanhaesebroeck B, Stephens L and Hawkins P: PI3K signalling: The path to discovery and understanding. Nat Rev Mol Cell Biol 13: 195-203, 2012.

39. Molina-Cerrillo J, Alonso-Gordoa T, Gajate P and Grande E: Bruton's tyrosine kinase (BTK) as a promising target in solid tumors. Cancer Treat Rev 58: 41-50, 2017.

40. Borisa AC and Bhatt HG: A comprehensive review on Aurora kinase: Small molecule inhibitors and clinical trial studies. Eur J Med Chem 140: 1-19, 2017

41. Damodaran AP, Vaufrey L, Gavard O and Prigent C: Aurora a kinase is a priority pharmaceutical target for the treatment of cancers. Trends Pharmacol Sci 38: 687-700, 2017.

42. Liu F, Wang G, Wang X, Che Z, Dong W, Guo X, Wang Z, Chen P, Hou D, Zhang Q, et al: Targeting high Aurora kinases expression as an innovative therapy for hepatocellular carcinoma. Oncotarget 8: 27953-27965, 2017.

43. Lai CH, Tseng JT, Lee YC, Chen YJ, Lee JC, Lin BW, Huang TC, Liu YW, Leu TH, Liu YW, et al: Translational up-regulation of Aurora-A in EGFR-overexpressed cancer. J Cell Mol Med 14: $1520-1531,2010$

44. Chen BP, Chan DW, Kobayashi J, Burma S, Asaithamby A, Morotomi-Yano K, Botvinick E, Qin J and Chen DJ: Cell cycle dependence of DNA-dependent protein kinase phosphorylation in response to DNA double strand breaks. J Biol Chem 280: $14709-14715,2005$

45. Falck J, Coates J and Jackson SP: Conserved modes of recruitment of ATM, ATR and DNA-PKcs to sites of DNA damage. Nature 434: 605-611, 2005.

46. Yajima H, Lee KJ, Zhang S, Kobayashi J and Chen BP: DNA double-strand break formation upon UV-induced replication stress activates ATM and DNA-PKcs kinases. J Mol Biol 385: 800-810, 2009.

47. Weterings E and Chen DJ: The endless tale of non-homologous end-joining. Cell Res 18: 114-124, 2008.

48. Hsu FM, Zhang S and Chen BP: Role of DNA-dependent protein kinase catalytic subunit in cancer development and treatment. Transl Cancer Res 1: 22-34, 2012.

49. Munck JM, Batey MA, Zhao Y, Jenkins H, Richardson CJ, Cano C, Tavecchio M, Barbeau J, Bardos J, Cornell L, et al: Chemosensitization of cancer cells by KU-0060648, a dual inhibitor of DNA-PK and PI-3K. Mol Cancer Ther 11: 1789-1798, 2012.

50. Chen MB, Zhou ZT, Yang L, Wei MX, Tang M, Ruan TY, Xu JY, Zhou XZ, Chen G and Lu PH: KU-0060648 inhibits hepatocellular carcinoma cells through DNA-PKcs-dependent and DNA-PKcs-independent mechanisms. Oncotarget 7: $17047-17059,2016$ 
51. Evert M, Frau M, Tomasi ML, Latte G, Simile MM, Seddaiu MA, Zimmerman A, Ladu S, Stansca T, Brozzetti S, et al: Deregulation of DNA-dependent protein kinase catalytic subunit contributes to human hepatocarcinogenesis development and has a putative prognostic value. Br J Cancer 109: 2654-2664, 2013.

52. Cornell L, Munck JM, Alsinet C, Villanueva A, Ogle L, Willoughby CE, Televantou D, Thomas HD, Jackson J, Burt AD, et al: DNA-PK-A candidate driver of hepatocarcinogenesis and tissue biomarker that predicts response to treatment and survival. Clin Cancer Res 21: 925-933, 2015.

53. Tu Y, Ji C, Yang B, Yang Z, Gu H, Lu CC, Wang R, Su ZL, Chen B, Sun WL, et al: DNA-dependent protein kinase catalytic subunit (DNA-PKcs)-SIN1 association mediates ultraviolet B (UVB)-induced Akt Ser-473 phosphorylation and skin cell survival. Mol Cancer 12: 172, 2013.

54. Li Y, Wang X, Yue P, Tao H, Ramalingam SS, Owonikoko TK, Deng X, Wang Y, Fu H, Khuri FR and Sun SY: Protein phosphatase $2 \mathrm{~A}$ and DNA-dependent protein kinase are involved in mediating rapamycin-induced Akt phosphorylation. J Biol Chem 288: 13215-13224, 2013.

55. Shi JL, Fu L and Wang WD: High expression of inositol 1,4,5-trisphosphate receptor, type 2 (ITPR2) as a novel biomarker for worse prognosis in cytogenetically normal acute myeloid leukemia. Oncotarget 6: 5299-5309, 2015.

56. Zhang F, Wen Y, Guo X, Zhang Y, Wang X, Yang T, Shen H, Chen X, Tian Q and Deng HW: Genome-wide association study identifies ITPR 2 as a susceptibility gene for Kashin-Beck disease in Han Chinese. Arthritis Rheumatol 67: 176-181, 2015.

57. Wiel C, Lallet-Daher H, Gitenay D, Gras B, Le Calvé B, Augert A, Ferrand M, Prevarskaya N, Simonnet H, Vindrieux D and Bernard D: Endoplasmic reticulum calcium release through ITPR2 channels leads to mitochondrial calcium accumulation and senescence. Nat Commun 5: 3792, 2014.

58. Yildiz G, Arslan-Ergul A, Bagislar S, Konu O, Yuzugullu H, Gursoy-Yuzugullu O, Ozturk N, Ozen C, Ozdag H, Erdal E, et al: Genome-wide transcriptional reorganization associated with senescence-to-immortality switch during human hepatocellular carcinogenesis. PLoS One 8: e64016, 2013.

59. Thoresen SB, Pedersen NM, Liest $\varnothing 1 \mathrm{~K}$ and Stenmark H: A phosphatidylinositol 3-kinase class III sub-complex containing VPS15, VPS34, Beclin 1, UVRAG and BIF-1 regulates cytokinesis and degradative endocytic traffic. Exp Cell Res 316: 3368-3378, 2010.

60. Kristensen L, Kristensen T, Abildgaard N, Thomassen M Frederiksen M, Mouritis-Andersen T and Møller MB: High expression of PI3K core complex genes is associated with poor prognosis in chronic lymphocytic leukemia. Leuk Res 39: 555-560, 2015

61. Alberobello AT, Wang Y, Beerkens FJ, Conforti F, McCutcheon JN, Rao G, Raffeld M, Liu J, Rahhal R, Zhang YW and Giaccone G: PI3K as a potential therapeutic target in thymic epithelial tumors. J Thorac Oncol 11: 1345-1356, 2016.

62. Shull AY, Latham-Schwark A, Ramasamy P, Leskoske K, Oroian D, Birtwistle MR and Buckhaults PJ: Novel somatic mutations to PI3K pathway genes in metastatic melanoma. PLoS One 7: e43369, 2012.

63. Huang J, Zhang L, Greshock J, Colligon TA, Wang Y, Ward R, Katsaros D, Lassus H, Butzow R, Godwin AK, et al: Frequent genetic abnormalities of the PI3K/AKT pathway in primary ovarian cancer predict patient outcome. Genes Chromosomes Cancer 50: 606-618, 2011.
64. Zheng YS, Zhang JY and Zhang DH: Fatsioside A-induced apoptotic death of HepG2 cells requires activation of AMP-activated protein kinase. Mol Med Rep 12: 5679-5684, 2015.

65. Ishijima N, Kanki K, Shimizu H and Shiota G: Activation of AMP-activated protein kinase by retinoic acid sensitizes hepatocellular carcinoma cells to apoptosis induced by sorafenib. Cancer Sci 106: 567-575, 2015.

66. Yie Y, Zhao S, Tang Q, Zheng F, Wu J, Yang L, Deng S and Hann SS: Ursolic acid inhibited growth of hepatocellular carcinoma HepG2 cells through AMPK $\alpha$-mediated reduction of DNA methyltransferase 1. Mol Cell Biochem 402: 63-74, 2015.

67. Zhang H, Li N, Wu J, Su L, Chen X, Lin B and Luo H: Galangin inhibits proliferation of HepG2 cells by activating AMPK via increasing the AMP/TAN ratio in a LKB1-independent manner. Eur J Pharmacol 718: 235-244, 2013.

68. Xieraili M, Yasen M, Mogushi K, Obulhasim G, Mayinuer A, Aihara A, Tanaka S, Mizushima H, Tanaka H and Arii S: Villin 1 is a predictive factor for the recurrence of high serum alpha-fetoprotein-associated hepatocellular carcinoma after hepatectomy. Cancer Sci 103: 1493-1501, 2012.

69. Buta C, Benabou E, Lequoy M, Régnault H, Wendum D, Meratbene F, Chettouh H, Aoudjehane L, Conti F, Chrétien Y, et al: Heregulin-1ß and HER3 in hepatocellular carcinoma: Status and regulation by insulin. J Exp Clin Cancer Res 35: 126, 2016.

70. Hsieh SY, He JR, Yu MC, Lee WC, Chen TC, Lo SJ, Bera R, Sung CM and Chiu CT: Secreted ERBB3 isoforms are serum markers for early hepatoma in patients with chronic hepatitis and cirrhosis. J Proteome Res 10: 4715-4724, 2011.

71. Gray KA, Yates B, Seal RL, Wright MW and Bruford EA: Genenames.org: The HGNC resources in 2015. Nucleic Acids Res 43 (Database Issue): D1079-D1085, 2015.

72. Hay R, Park JG and Gazdar A (eds): Atlas of human tumor cell lines. Academic Press Inc., California, pp185-212, 1994.

73. Yuzugullu H, Benhaj K, Ozturk N, Senturk S, Celik E, Toylu A, Tasdemir N, Yilmaz M, Erdal E, Akcali KC, et al: Canonical Wnt signaling is antagonized by noncanonical Wnt5a in hepatocellular carcinoma cells. Mol Cancer 8: 90, 2009.

74. Cevik D, Yildiz G and Ozturk M: Common telomerase reverse transcriptase promoter mutations in hepatocellular carcinomas from different geographical locations. World J Gastroenterol 21: 311-317, 2015

75. Zhao H, Desai V, Wang J, Epstein DM, Miglarese M and Buck E: Epithelial-mesenchymal transition predicts sensitivity to the dual IGF-1R/IR inhibitor OSI-906 in hepatocellular carcinoma cell lines. Mol Cancer Ther 11: 503-513, 2012.

76. Nozaki I, Tsuji T, Sakaguchi M, Inoue Y, Hirai R, Andou A, Miyazaki M, Shimizu N and Namba M: Establishment of a human hepatoma cell line, HLE/2E1, suitable for detection of p450 2E1-related cytotoxicity. In Vitro Cell Dev Biol Anim 36: 566-570, 2000 .

This work is licensed under a Creative Commons Attribution-NonCommercial-NoDerivatives 4.0 International (CC BY-NC-ND 4.0) License. 